\title{
Correction: Phylogeography of the iconic Australian red-tailed black- cockatoo (Calyptorhynchus banksii) and implications for its conservation
}

Kyle M. Ewart (D) N Nathan Lo · Rob Ogden • Leo Joseph • Simon Y. W. Ho D - Greta J. Frankham • Mark D. B. Eldridge • Richard Schodde - Rebecca N. Johnson (D)

Published online: 21 July 2020

(c) The Author(s), under exclusive licence to The Genetics Society 2020

Correction to: Heredity

https://doi.org/10.1038/s41437-020-0315-y

The original version of this article was updated shortly after publication to correct the description of phylogenetic model comparison and update Table 2. The model rankings and conclusion are unaffected.

This has now been corrected in both the PDF and HTML versions of the article. 